Los patógenos asociados con enfermedades emergentes y reemergentes tienen algunas características comunes. En primer lugar, en ambos casos predominan los virus, en particular los virus de ARN (37\% de las especies virales asociadas con enfermedades emergentes y reemergentes). En segundo lugar, estos patógenos no están asociados con un hospedero animal específico y pueden vivir en las más disímiles especies animales, ya sean mamíferos o no. Además, los patógenos emergentes y reemergentes poseen una flexibilidad biológica que les permite aprovechar las oportunidades epidemiológicas que se presentan. Esta característica se manifiesta en la amplia gama de situaciones que llevan a la aparición de enfermedades emergentes o reemergentes, desde los cambios en el terreno y la agricultura hasta el número de hospitalizaciones y el tráfico internacional de personas.

La magnitud de un brote infeccioso está relacionada con la reproducción del patógeno. En el caso de los patógenos que se transmiten muy poco dentro de una población humana, el tamaño de los brotes está determinado en gran medida por el número de patógenos introducidos en ella. Cuando el patógeno es altamente transmisible, el tamaño del brote está determinado fundamentalmente por el tamaño de la población susceptible. Sin embargo, cuando la capacidad de transmisión del patógeno dentro de una población es moderada, el tamaño del brote puede variar ampliamente a partir de pequeños cambios en el número de patógenos introducidos. No obstante, hasta el momento no se conocen factores que permitan predecir si un nuevo patógeno se comportará como el virus de la rabia (que una vez introducido en una población humana no causa grandes epidemias) o como el virus de la inmunodeficiencia humana (que una vez introducido, aun en mínimas cantidades, puede ocasionar grandes pandemias).

Este estudio permite concluir que es posible conocer las características biológicas y epidemiológicas que llevan a la emergencia o reemergencia de un patógeno. Sin embargo, la principal característica de los patógenos emergentes y reemergentes es su gran diversidad. Por esta razón, la vigilancia de las tendencias que manifiestan las enfermedades infecciosas debe intensificarse. Dado que alrededor de 75\% de los patógenos que ocasionan enfermedades emergentes o reemergentes utilizan algún vector $u$ hospedero animal, la vigilancia debe extenderse más allá de las poblaciones en riesgo y abarcar los posibles reservorios de estos animales. (Woolhouse $\mathrm{MEJ}$, et al. Host range and emerging and reemerging pathogens. Emerg Infect Dis [publicación periódica en línea]. 2005;11:1842-7. Hallado en: http://www.cdc.gov/ncidod/EID/vol11no12/050997.htm. Acceso el 1 de diciembre de 2005).

\section{Tasas de discapacidad en adultos mayores de América Latina y el Caribe}

Se calcula que alrededor de 3 a $6 \%$ de las personas de 65 a 74 años de edad que viven en los Estados Unidos de América presentan dificultades para realizar al menos una actividad instrumental de la vida diaria (AIVD) o una actividad de la vida diaria (AVD) y que este porcentaje es de 10-20\% en personas de 75 años o más. La discapacidad de las personas de mayor edad está asociada con su mayor riesgo de hospitalización, morbilidad y muerte. Recientemente, la Organización Panamericana de la Salud promovió un estudio multinacional con el objetivo de evaluar las tasas de dificultad para realizar AIVD y AVD en adultos mayores de América Latina y el Caribe y evaluar los factores sociodemográficos y sanitarios asociados con estas discapacidades.

El estudio Salud, Bienestar y Envejecimiento en América Latina y el Caribe (SABE) se basó en una encuesta transversal realizada entre 1999 y 2000 a 10970 hombres y mujeres de 60 años de edad o más que vivían en siete ciudades. Para el presente análisis se utilizaron los datos de 3225 personas de 75 años o más que fueron entrevistadas (290 de Buenos Aires, Argentina; 581 de Bridgetown, Barbados; 791 de São Paulo, Brasil; 389 de Santiago, Chile; 555 de La Habana, Cuba; 245 de México, D.F., México; y 374 de Montevideo, Uruguay).

Se encontró que la dificultad para realizar AIVD y AVD aumentaba con la edad en todos los países, era mayor en las mujeres que en los hombres y estaba asociada con una menor escolaridad, un índice de masa corporal $<20$ y el padecimiento de un mayor número de enfermedades. Las personas de mayor edad de São Paulo y Santiago presentaron mayores dificultades para realizar AIVD $(33,8 \%$ y $30,3 \%$, respectivamente) que las de otras ciudades, mientras que en Montevideo y Bridgetown se encontró el menor número de personas con estas dificultades (12,0\% y 18,1\%, respectivamente). En cuanto a la dificultad para realizar AVD, las ciudades con mayor prevalencia fueron Santiago $(34,7 \%)$ y Buenos Aires $(32,1 \%)$ y las menos afectadas fueron Bridgetown $(16,9 \%)$ y Montevideo (23,5\%). Las mayores dificultades estuvieron relacionadas con caminar, trasladarse y bañarse. El ser mujer mostró una asociación significativa con la dificultad para realizar AIVD, pero no AVD.

La gran heterogeneidad encontrada en cuanto a las dificultades para realizar AIVD y AVD en los diferentes países estudiados puede deberse a las diferencias en la escolaridad media de sus adultos mayores, a factores culturales (algunas sociedades protegen más a las personas de mayor edad) o al diferente nivel de desarrollo de las infraestructu- 
ras que facilitan la movilidad de las personas de mayor edad en esos países. (Reyes-Ortiz CA, et al. Cross-national comparison of disability in Latin American and Caribbean persons aged 75 and older. Arch Gerontol Geriatr. 2006;42:21-33).

\section{Revisión sistemática de estudios sobre la epilepsia en América Latina}

La epilepsia es la enfermedad neurológica grave más frecuente en el mundo, especialmente en los países en desarrollo, donde se detecta el $85 \%$ de los casos. Los datos de la incidencia de la epilepsia en América Latina muestran una gran heterogeneidad. En este trabajo se ofrecen los resultados de una revisión sistemática de los estudios retrospectivos y prospectivos basados en la comunidad que evaluaron la prevalencia y la incidencia de la epilepsia en adultos y niños de América Latina. Se analizaron los trabajos que emplearon cuestionarios validados previamente, encuestas y entrevistas y que se indizaron en las bases de datos bibliográficas MEDLINE, IMBIOMED y LILACS hasta julio de 2004.

Se encontraron 32 estudios de prevalencia y 3 de incidencia que cumplieron con los criterios de inclusión. La mediana de la prevalencia de toda la vida para todos los países fue de 17,8 por 1000 habitantes (mínimo: 6; máximo: 44,3), mientras que la mediana de la prevalencia de la epilepsia activa fue de 12,4 por 1000 habitantes (mínimo: 5,1; máximo: $57,0)$. No se encontraron diferencias significativas entre las prevalencias en hombres y mujeres.

Las tasas de incidencia por 100000 habitantes por año variaron entre 77,7 en Martinica y 190 en algunas partes de Ecuador. Esta gran heterogeneidad puede deberse a factores metodológicos, la calidad del diagnóstico, las particularidades de la población estudiada (edad, características socioeconómicas, lugar de residencia, etc.), los diferentes factores de riesgo e incluso a diferencias genéticas. Las variaciones en la prevalencia de esta enfermedad dentro de un mismo país son el reflejo de las diferencias entre las condiciones de vida de las diversas ciudades o regiones.

Los estudios epidemiológicos demostraron mayores tasas de prevalencia e incidencia de epilepsia en la población en general de América Latina que en los países del hemisferio norte. Es necesario identificar con mayor precisión las causas de esa heterogeneidad entre los países - y entre ciudades o regiones dentro de un mismo país-, mejorar los métodos de investigación y ampliar el conjunto de poblaciones estudiadas. Se deben escoger cuidadosamente las áreas de estudio y realizar estudios longitudinales que permitan tener una idea más clara no solamente de la incidencia, sino también de la morbilidad y mortalidad asociadas con la epilepsia. (Burneo JG, et al. Understanding the burden of epilepsy in Latin America: a systematic review of its prevalence and incidence. Epilepsy Res. 2005;66:63-74).

\section{Transmisión interpersonal del virus de los Andes}

El virus de los Andes (VA) es el único miembro americano del género Hantavirus que ha sido aislado de suero humano. Hasta el momento, seis cepas de VA han estado asociadas con casos de síndrome pulmonar por hantavirus en Argentina: la cepa VA sout en la región suroccidental; VA cent BsAs, VA cent Lec y VA cent Plata en la región central; y VA nort Orán y VA nort Bermejo en la región noroccidental. A pesar de que los roedores constituyen la vía principal de infección, se ha documentado la transmisión de la cepa VA sout de persona a persona.

En este trabajo se analizaron 13 casos de síndrome pulmonar por hantavirus que se detectaron en dos zonas con enfermedad endémica en Argentina durante 2002. En todos los casos se documentó la infección por hantavirus y en 10 de ellos se realizó la caracterización genética de la cepa responsable mediante el análisis nucleotídico de un fragmento de la región codificante G2 (desde la posición 2717 hasta la 2943).

Se identificaron cuatro conglomerados de casos según las relaciones epidemiológicas conocidas, entre los cuales se detectaron tres casos de transmisión de persona a persona. La comparación de las secuencias nucleotídicas de los virus de los cuatro conglomerados epidemiológicos demostró la identidad total entre los casos de un mismo conglomerado. La cepa VA cent BsAs se encontró en tres de los conglomerados, mientras que la cepa VA sout se encontró en tres casos de un conglomerado del suroeste del país, lo que constituye el primer informe de esta cepa en esa región argentina. Los casos de tres de los conglomerados tuvieron características clínicas similares entre sí, aunque diferentes de las de los casos encontrados en Buenos Aires. El período de incubación fue de 15 a 26 días.

Los resultados de este trabajo demuestran que la transmisión del virus de los Andes de una persona a otra es posible durante la fase prodrómica o inmediatamente después de ella. Las pruebas acumuladas hasta el momento indican que si bien los contactos esporádicos con personas en los primeros estadios del síndrome pulmonar por hantavirus no representan un riesgo de infección, se debe prestar atención a los contactos que ocurren en sitios cerrados, como los vehículos o el ambiente laboral. 